\title{
Upgrading of Light Dewaxed Oil through Hydrofinishing and Additives Blending for Producing Automatic Transmission Fluid
}

\author{
${ }^{1}$ Gamal Abdel-Nasser Gohar, ${ }^{1}$ Mohamed Sherif El-Gayar, \\ ${ }^{1}$ Abd El-Moneim Ibrahim ${ }^{2}$ Hany, ${ }^{3}$ Marwan and Ahmed Aly \\ ${ }^{1}$ Chemistry Department, Faculty of Science, Alexandria University, Egypt \\ ${ }^{2}$ Egyptian Petrochemicals Holding Company, Nasser City, Cairo, Egypt \\ ${ }^{3}$ Alexandria Mineral Oils Company (AMOC), Alexandria, Egypt. P.O. Box (5) El Max
}

\begin{abstract}
Light dewaxed oil was produced through dewaxing process of the light waxy distillate raffinate of crude oil from Western Desert of Egypt using methyl ethyl ketone/toluene mixed solvent. Hydrofinishing process was used to remove the non-hydrocarbon constituents and to improve the physicochemical properties of the produced oils such as color, viscosity index, inhibition responses, oxidation and thermal stability. The operating parameters which affected the quality of the hydrofinished oils were studied separately at different values that including reactor temperature, reactor pressure, liquid hourly space velocity and hydrogen to hydrocarbon ratio. The optimum operating conditions to be adopted for producing high quality automatic transmission fluid base oil were reactor temperature $290{ }^{\circ} \mathrm{C}$, pressure $130 \mathrm{~kg} \mathrm{~cm}^{-2}$, liquid hourly space velocity $0.4 \mathrm{~h}^{-1}$ and hydrogen/hydrocarbon ratio $800 \mathrm{Nm}^{3} \mathrm{M}^{-3}$. The effect of changing hydrofinishing temperature and liquid hourly space velocity on the hydrodesulfurization (HDS) and hydrodenitrogenation (HDN) reactions as well as their thermodynamic parameters were estimated. Calculations of activation energy (Ea) and free energy of activation $(\Delta G)$ indicated that HDS was easier to occur than HDN and these reactions are more faster at higher temperatures. The effect of commercial and formulated additives on the quality of the hydrofinished oil was also studied. Automatic transmission fluid possessing the Dexron IID specification was produced by adding $7 \mathrm{wt} \%$ from Infenium T442 additive or by adding 9 wt\% from Lubrizol ® $6701 \mathrm{D}$ additive to the hydrofinished light dewaxed oil. Oils with the same efficiency were also produced using a formulated additive containing $4 \%$ viscosity index improver, $1.5 \%$ anti-oxidant and 1\% anti-wear. The effect of increasing Infenium T442, Lubrizol R $6701 \mathrm{D}$ and formulated additive percents on the protection efficiency of the automatic transmission fluid was studied through AC impedance technique. According to this technique, the effect of these additives on the corrosion rate of carbon steel coupons can be negligible.
\end{abstract}

Key words: Light dewaxed oil, raffinate, hydrodesulfurization, hydrodenitrogenation, automatic transmission fluid

\section{INTRODUCTION}

Lubricating oils play a crucial role in both domestic and industrial processes. Proper applications of lubricants increase the lifetime and efficiency of machinery and decrease long-term costs in terms of energy consumption, maintenance requirements and reduce operating temperatures. Lubricants are used for the following requirements: minimizing frictions at the interfaces, protection of the sensitive surfaces from rust and corrosion, the dissipation of the heat generated in the interfaces, help in the creation of seals, neutralize residues and removal or prevention of the interference of foreign matters into the interfaces. Lubricants selection depends upon the type of equipment, temperature range, loading, oxidation stability, volatility, system compatibility, foaming potential, dispersant, detergency requirements, as well as demulsification or emulsification properties ${ }^{[1-5]}$.

Petroleum mineral oils, which have many applications, are produced from the residue of atmospheric distillation. The initial process that determine the grade of the produced base oil is the refining of feedstocks through vacuum distillation of fuel oils ${ }^{[6-8]}$. Spindle oil, light waxy distillate (LWD), medium waxy distillate (MWD) and heavy waxy distillate (HWD) are used to produce special and neutral oils, while the vacuum residue is used to produce bright stock oil after propane deasphalting ${ }^{[9-11]}$.

The automatic transmission fluids (ATFs) are the most important lubricating oils which are used in many purposes, including heat dissipation, wear protection, lubrication, foam inhibition and shift quality. It is usually produced by hydrofinishing the light dewaxed

Corresponding Author: Gamal A. Gohar, Chemistry Department, Faculty of Science, Alexandria University, Alexandria, Egypt, Tel: +203/5927665, Fax: +203/5932488 
oil (LDWO) to remove the trace amounts of sulfur, oxygen, nitrogen and organometalic compounds as well as aromatic contents which affect the oil properties during applications and result in rapid darkening, oxidation and sludging in service ${ }^{[12]}$.

Most base oil additives are chemical compounds of non-petroleum origin. They are frequently used either to reinforce existing properties or create additional properties $^{[13,14]}$. However, individual base oils have different response to particular additives and it is necessary to search for additives which give the maximum performance ${ }^{[15]}$.

In view of these considerations, the LDWO of Egyptian crude oils produced from Western Desert region were hydrofinished using catalyst mixtures of $\mathrm{NiO}$ and $\mathrm{MoO}_{3}$ supported on alumina where $\mathrm{NiO}$ acts as a promoter on crystallites of $\mathrm{MoO}_{3}$. The effects of the reactor temperature, pressure, space velocity and hydrogen to hydrocarbon ratio on the quality of the hydrofinished oil in the presence of this type of catalyst were investigated in order to reach the best operating conditions. The compatibility and the effect of commercial and formulated additives on the physicochemical properties of the Western Desert LDWO were also studied. The objective of adding these specified materials to the hydrofinished oil is to produce ATF Dexron IID which is recommended for passenger car. ATF Dexron IID is characterized by excellent oxidation stability and deposit control under very high temperature and severe operating conditions, excellent antiwear properties, good antifoam, antirust and anticorrosion properties, low volatility to provide minimum evaporation loss and compatible with severe types of synthetic rubber ${ }^{[16-19]}$.

\section{DATA AND METHODOLOGY}

The LDWOs of a crude oils from the Western Desert of Egypt were used in this investigation. Table 1 lists the physicochemical properties of the feedstock tested according to ASTM and IP standard methods ${ }^{[20,21]}$. The hydrofinishing process of LDWO were carried out in plant designed by Institute Francias Dupetrol (IFP) (Fig. 1). In this process, the LDWO is mixed with hydrogen, heated to the reaction temperature and passed down flow over the fixed bed of catalyst. Hydrogen quench is used to remove the generated heat and control the reaction temperature. The reactor effluent passes through a series of separators to remove the hydrogen and other light gases from the hydrofinished light dewaxed oil ${ }^{[22,23]}$. An industrial $\mathrm{NiO}-\mathrm{MoO}_{3} / \mathrm{Al}_{2} \mathrm{O}_{3}$ catalyst, supplied by Procatalyse-France, was presulfided in presence of hydrogen. Sulfiding process is carried out with dimethyl disulfide, which easily decomposed into hydrogen sulfide, in order to convert the catalyst to its active form. Operating without sulfiding process will cause feedstock cracking as well as coke deposition and

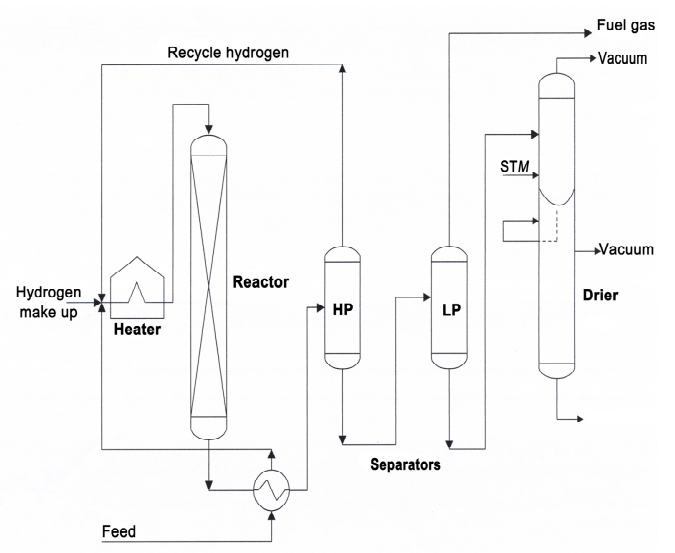

Fig. 1: Process flow for the hydrofinishing plant designed by the Institute Francais Dupetrol

rapid deactivation of the catalyst. The effect of reactor temperature, the applied pressure, liquid hourly space velocity and hydrogen to hydrocarbon ratio on the physicochemical properties of the products were studied $^{[24]}$.

The hydrofinished LDWO was mixed with the multipurpose ATF additives; InfeniumT442 and Lubrizol ${ }^{\circledR} 6701 \mathrm{D}$ by the percentage of $5,6,7,8,9$, $10,11,12$ and $13 \%$, wt for both. Infenium T442 is lubricant additive containing polyolefin amide alkyleneamine, poly long chain alkylmethacrylate, zinc alkyl dithiophosphate and other components dissolved in highly refined mineral oil, supplied by Infenium UK Limited, Abingdon, Oxfordshire. Lubrizol ${ }^{\circledR}$ 6701D is a multipurpose package for automatic transmission fluids supplied from a local company ACPA, Cairo, Egypt. The formulated additive was prepared by adding different percentages of viscosity index (VI) improver (ACPA, SV 261) namely ; 2, 2.5, 3, 3.5, 4, 4.5, 5, 5.5 and 6\% wt, 1.5\% wt anti-oxidant (Vanlube R 961) and $1 \%$ wt anti-wear (Angalamole 6085).

AC impedance technique was applied to study the effect of the increased sulfur and total acidity, due to increasing additive percents, on the corrosion rates of carbon steel coupons that may be contact the ATF during use.

\section{METHODS OF CALCULATIONS}

Calculation of activation energy and thermodynamic parameters of HDS and HDN reactions:

The effect of temperature on the rate of hydrogenation reactions according to the integrated form of the Arrhenius equation ${ }^{[25,26]}$ :

$\mathrm{K}=\mathrm{A} \mathrm{e} \mathrm{e}^{\text {-Ea/RT }}$

$\mathrm{A}=$ factor in the Arrhenius equations

$\mathrm{Ea}=$ apparent activation energy $\left(\mathrm{K} \mathrm{J} \mathrm{mol}^{-1}\right)$

$\mathrm{R}=$ universal gas constant $\left(\mathrm{J} \mathrm{K}^{-1} \mathrm{~mol}^{-1}\right)$

$\mathrm{T}=$ absolute reaction temperature $(\mathrm{K})$

The values for the enthalpy of activation $\Delta \mathrm{H}$, entropy of activation $\Delta S$ and free energy of activation 
Am. J. Applied Sci., 3 (12): 2136-2146, 2006

Table 1: Effect of the hydrogen/feed ratio, pressure, temperature and LHSV on the hydrofinishing of LDWO

\begin{tabular}{|c|c|c|c|c|c|c|c|c|c|c|c|c|}
\hline \multirow{2}{*}{ Properties } & \multirow{2}{*}{ Feed } & \multicolumn{6}{|c|}{ Hydrogen / feed ratio $\left(\mathrm{Nm}^{3} / \mathrm{M}^{3}\right)$} & \multicolumn{5}{|c|}{ Pressure $\left(\mathrm{kg} / \mathrm{cm}^{2}\right)$} \\
\hline & & 400 & 600 & 800 & 1000 & 1200 & 1400 & 100 & 110 & 120 & 130 & 135 \\
\hline Sp. gr. at $60 / 60^{\circ} \mathrm{F}$, & 0.8699 & 0.8671 & 0.8662 & 0.8647 & 0.8638 & 0.8631 & 0.8624 & 0.8681 & 0.8669 & 0.8658 & 0.8647 & 0.8640 \\
\hline $\begin{array}{l}\text { Refractive index at } \\
70^{\circ} \mathrm{C}\end{array}$ & 1.4598 & 1.4582 & 1.4566 & 1.4555 & 1.4547 & 1.4540 & 1.4533 & 1.4586 & 1.4578 & 1.4566 & 1.4555 & 1.4549 \\
\hline Saybolt color & $\begin{array}{l}<\quad 1.5 \\
(\text { ASTM })\end{array}$ & +14 & +18 & +24 & +26 & +28 & +30 & +8 & +14 & +20 & +24 & +28 \\
\hline $\begin{array}{l}\text { Kin.vis. at } 100{ }^{\circ} \mathrm{C} \text {, } \\
\text { cSt }\end{array}$ & 3.86 & 3.84 & 3.81 & 3.78 & 3.73 & 3.69 & 3.67 & 3.85 & 3.83 & 3.81 & 3.78 & 3.75 \\
\hline $\begin{array}{l}\text { Kin.vis. at } 40{ }^{\circ} \mathrm{C} \text {, } \\
\text { cSt }\end{array}$ & 18.66 & 18.45 & 18.36 & 17.92 & 17.47 & 17.06 & 16.91 & 18.58 & 18.37 & 18.21 & 17.92 & 17.63 \\
\hline Viscosity index & 96 & 97 & 97 & 98 & 99 & 101 & 101 & 96 & 97 & 97 & 98 & 98 \\
\hline Sulfur content, ppm & 8800 & 480 & 390 & 310 & 240 & 190 & 170 & 570 & 440 & 360 & 310 & 270 \\
\hline $\begin{array}{l}\text { Nitrogen content, } \\
\text { ppm }\end{array}$ & 57 & 27 & 19 & 13 & 10 & 7 & 5 & 31 & 24 & 19 & 13 & 12 \\
\hline Pour point, ${ }^{\circ} \mathrm{C}$ & -30 & -30 & -27 & -27 & -24 & -24 & -21 & -30 & -30 & -27 & -27 & -27 \\
\hline $\begin{array}{l}\text { Acidity, } \\
\mathrm{KOH} / \mathrm{gm}\end{array}$ & 0.021 & 0.017 & 0.014 & 0.012 & 0.01 & 0.007 & 0.005 & 0.018 & 0.016 & 0.013 & 0.012 & 0.012 \\
\hline $\begin{array}{l}\text { Carbon residue, wt } \\
\%\end{array}$ & 0.072 & 0.068 & 0.062 & 0.059 & 0.055 & 0.049 & 0.046 & 0.067 & 0.064 & 0.061 & 0.059 & 0.057 \\
\hline $\begin{array}{l}\text { UV } \\
\text { absorbance@275nm }\end{array}$ & 1.153 & 0.711 & 0.561 & 0.447 & 0.338 & 0.253 & 0.184 & 0.731 & 0.562 & 0.432 & 0.347 & 0.321 \\
\hline VGC at $70{ }^{\circ} \mathrm{C}$ & 0.8219 & 0.8187 & 0.8179 & 0.8164 & 0.8157 & 0.8152 & 0.8146 & 0.8198 & 0.8186 & 0.8174 & 0.8164 & 0.8158 \\
\hline Average M.wt & 380 & 375 & 370 & 360 & 350 & 345 & 340 & 375 & 370 & 365 & 360 & 350 \\
\hline $\mathrm{C}_{\mathrm{A}} \%$ & 5.97 & 5.33 & 3.32 & 2.76 & 2.30 & 1.74 & 1.18 & 5.31 & 4.91 & 3.74 & 2.76 & 2.50 \\
\hline $\mathrm{C}_{\mathrm{N}} \%$ & 25.39 & 28.22 & 31.27 & 32.50 & 33.88 & 34.99 & 36.11 & 28.56 & 29.17 & 30.97 & 32.50 & 33.66 \\
\hline $\mathrm{C}_{\mathrm{P}} \%$ & 68.64 & 66.45 & 65.41 & 64.65 & 63.82 & 63.27 & 62.71 & 66.13 & 65.92 & 65.29 & 64.65 & 63.84 \\
\hline
\end{tabular}

Table 1: Contd.

\begin{tabular}{|c|c|c|c|c|c|c|c|c|c|c|c|}
\hline \multirow{2}{*}{$\begin{array}{l}\text { Properties } \\
\text { Sp. gr. at } 60 / 60^{\circ} \mathrm{F}, \\
\end{array}$} & \multicolumn{3}{|c|}{ Temperature $\left({ }^{\circ} \mathrm{C}\right)$} & \multicolumn{5}{|c|}{$\operatorname{LHSV}\left(\mathrm{h}^{-1}\right)$} & \multirow[b]{2}{*}{0.4} & \multirow[b]{2}{*}{0.3} & \multirow[b]{2}{*}{0.25} \\
\hline & 250 & 270 & 290 & 310 & 330 & 350 & 0.6 & 0.5 & & & \\
\hline $\begin{array}{l}\text { Refractive index at } \\
70^{\circ} \mathrm{C}\end{array}$ & 0.8668 & 0.8659 & 0.8647 & 0.8636 & 0.8629 & 0.8638 & 0.8664 & 0.8656 & 0.8647 & 0.8634 & 0.8647 \\
\hline Saybolt color & 1.4581 & 1.4569 & 1.4555 & 1.4543 & 1.4536 & 1.4549 & 1.4579 & 1.4566 & 1.4555 & 1.4538 & 1.4547 \\
\hline Kin.vis. at $100{ }^{\circ} \mathrm{C}, \mathrm{cSt}$ & +6 & +18 & +24 & +28 & +30 & +22 & +12 & +18 & +24 & +30 & +22 \\
\hline Kin.vis. at $40{ }^{\circ} \mathrm{C}$, cSt & 3.83 & 3.80 & 3.78 & 3.74 & 3.70 & 3.76 & 3.82 & 3.80 & 3.78 & 3.73 & 3.79 \\
\hline Viscosity index & 18.37 & 18.12 & 17.92 & 17.55 & 17.14 & 17.71 & 18.34 & 18.13 & 17.92 & 17.42 & 17.94 \\
\hline Sulfur content, ppm & 97 & 97 & 98 & 99 & 101 & 99 & 96 & 97 & 98 & 100 & 99 \\
\hline $\begin{array}{l}\text { Nitrogen content, } \\
\text { ppm }\end{array}$ & 460 & 370 & 310 & 265 & 220 & 360 & 495 & 390 & 310 & 275 & 240 \\
\hline Pour point, ${ }^{\circ} \mathrm{C}$ & 24 & 18 & 13 & 11 & 8 & 6 & 26 & 20 & 13 & 11 & 9 \\
\hline Acidity, mg KOH/gm & -30 & -27 & -27 & -24 & -21 & -24 & -30 & -27 & -27 & -24 & -24 \\
\hline Carbon residue, wt \% & 0.016 & 0.014 & 0.012 & 0.009 & 0.008 & 0.015 & 0.015 & 0.013 & 0.012 & 0.010 & 0.008 \\
\hline $\begin{array}{l}\text { UV } \\
\text { absorbance@275nm }\end{array}$ & 0.065 & 0.061 & 0.059 & 0.048 & 0.041 & 0.049 & 0.063 & 0.060 & 0.059 & 0.045 & 0.042 \\
\hline VGC at $70{ }^{\circ} \mathrm{C}$ & 0.723 & 0.591 & 0.347 & 0.311 & 0.272 & 0.525 & 0.697 & 0.481 & 0.347 & 0.291 & 0.416 \\
\hline Average M.wt & 0.8185 & 0.8176 & 0.8164 & 0.8152 & 0.8146 & 0.8155 & 0.8181 & 0.8173 & 0.8164 & 0.8153 & 0.8163 \\
\hline $\mathrm{C}_{\mathrm{A}} \%$ & 370 & 365 & 360 & 350 & 340 & 360 & 375 & 370 & 360 & 345 & 365 \\
\hline $\mathrm{C}_{\mathrm{N}} \%$ & 5.50 & 4.19 & 2.76 & 1.75 & 1.34 & 1.64 & 5.31 & 3.75 & 2.76 & 1.17 & 1.23 \\
\hline $\mathrm{C}_{\mathrm{P}} \%$ & 28.24 & 30.34 & 32.50 & 34.61 & 36.06 & 34.25 & 27.87 & 30.37 & 32.50 & 35.94 & 34.30 \\
\hline & 66.26 & 65.47 & 64.65 & 63.64 & 62.60 & 64.11 & 66.82 & 65.88 & 64.65 & 62.84 & 64.47 \\
\hline
\end{tabular}

$\Delta \mathrm{G}$ can be calculated by using the following equations $^{[25,26]}$ :

$\Delta \mathrm{H}=\mathrm{E}-\mathrm{RT}$

$\Delta \mathrm{S} / \mathrm{R}=\ln \mathrm{A}-\ln \mathrm{BTe} / \mathrm{h}$

$\Delta \mathrm{G}=\Delta \mathrm{H}-\mathrm{T} \Delta \mathrm{S}$

Where, B is Boltzman constant, $1.3805 \times 10^{-16} \mathrm{erg}$

$\mathrm{H}$ is plank's constant, $6.6242 \times 10^{-27} \mathrm{erg}$

$\mathrm{e}=2.7183$

Calculation of the protection efficiency through impedance measurements: The protection efficiency $\mathrm{P}$, of any particular compound was calculated from the impedance data by applying the following relation ${ }^{[27]}$ :

$$
\mathrm{P}=100\left[1-\frac{\left(1 / \mathrm{R}_{\mathrm{p}}\right)}{\left(1 / \mathrm{R}_{\mathrm{p}}\right)_{0}}\right.
$$

Where $\left(1 / R_{p}\right)_{0}$ and $\left(1 / R_{p}\right)$ are reciprocal of the charge transfer resistance in the absence and presence of a certain concentration of the additive respectively.

\section{RESULTS AND DISCUSSION}

Hydrofinishing operating parameters and the production of ATF: The production of ATF from LDWO through the catalytic hydrofinishing process and the influence of different operating parameters on the process have been studied. 
Am. J. Applied Sci., 3 (12): 2136-2146, 2006

Table 2: Effect of hydrofinishing temperature and LHSV on the sulfur and nitrogen contents of LDWO. Hydrofinishing conditions: hydrogen to feedstock ratio $=800 \mathrm{Nm}^{3} / \mathrm{M}^{3}$, pressure $=130 \mathrm{~kg} / \mathrm{cm}^{2}$, sulfur of feed $\left(\mathrm{S}_{\text {in }}\right)=8800 \mathrm{ppm}$, nitrogen of feed $\left(\mathrm{N}_{\text {in }}\right)=57 \mathrm{ppm}$

\begin{tabular}{|c|c|c|c|c|c|c|c|c|c|c|c|}
\hline $\mathrm{T},{ }^{\circ} \mathrm{C}$ & $\operatorname{LHSV}\left(\mathrm{h}^{-1}\right)$ & $\mathrm{S}^{(\mathrm{a})}{ }_{\text {out }}(\mathrm{ppm})$ & $\mathrm{S}_{\text {in }} / \mathrm{S}_{\text {out }}$ & $\mathrm{N}^{(\mathrm{a})}{ }_{\text {out }}(\mathrm{ppm})$ & $\mathrm{N}_{\text {in }} / \mathrm{N}_{\text {out }}$ & $\mathrm{T},{ }^{\circ} \mathrm{C}$ & $\operatorname{LHSV}\left(\mathrm{h}^{-1}\right)$ & $\mathrm{S}^{(\mathrm{a})}{ }_{\text {out }}(\mathrm{ppm})$ & $\mathrm{S}_{\text {out }} / \mathrm{S}_{\text {in }}$ & $\mathrm{N}^{(\mathrm{a})}{ }_{\text {out }}(\mathrm{ppm})$ & $\mathrm{N}_{\text {int }} / \mathrm{N}_{\text {out }}$ \\
\hline \multirow{5}{*}{190} & 0.6 & 695 & 12.662 & 40 & 1.425 & \multirow{5}{*}{250} & 0.6 & 550 & 16.000 & 31 & 1.839 \\
\hline & 0.5 & 525 & 16.762 & 34 & 1.677 & & 0.5 & 435 & 20.230 & 26 & 2.192 \\
\hline & 0.4 & 455 & 19.341 & 29 & 1.966 & & 0.4 & 355 & 24.789 & 21 & 2.714 \\
\hline & 0.3 & 390 & 22.564 & 27 & 2.111 & & 0.3 & 315 & 27.937 & 18 & 3.167 \\
\hline & 0.25 & 350 & 25.143 & 22 & 2.591 & & 0.25 & 280 & 31.429 & 14 & 4.071 \\
\hline \multirow{5}{*}{210} & 0.6 & 640 & 13.750 & 37 & 1.541 & \multirow{5}{*}{270} & 0.6 & 520 & 16.923 & 28 & 2.036 \\
\hline & 0.5 & 490 & 17.959 & 31 & 1.839 & & 0.5 & 410 & 21.463 & 23 & 2.478 \\
\hline & 0.4 & 420 & 20.953 & 26 & 2.192 & & 0.4 & 325 & 27.077 & 17 & 3.353 \\
\hline & 0.3 & 365 & 24.110 & 23 & 2.478 & & 0.3 & 290 & 30.345 & 14 & 4.071 \\
\hline & 0.25 & 325 & 27.077 & 19 & 3.000 & & 0.25 & 255 & 34.510 & 12 & 4.750 \\
\hline \multirow{5}{*}{230} & 0.6 & 590 & 14.915 & 33 & 1.727 & \multirow{5}{*}{290} & 0.6 & 495 & 17.778 & 26 & 2.192 \\
\hline & 0.5 & 460 & 19.130 & 29 & 1.966 & & 0.5 & 390 & 22.564 & 20 & 2.850 \\
\hline & 0.4 & 380 & 23.158 & 24 & 2.375 & & 0.4 & 310 & 28.387 & 13 & 4.385 \\
\hline & 0.3 & 335 & 26.269 & 20 & 2.850 & & 0.3 & 275 & 32.000 & 11 & 5.182 \\
\hline & 0.25 & 300 & 29.333 & 17 & 3.353 & & 0.25 & 240 & 36.667 & 9 & 6.333 \\
\hline \multirow[t]{2}{*}{$\frac{\text { lable }}{\mathrm{T},{ }^{\circ} \mathrm{C}}$} & \multicolumn{2}{|r|}{$\left.\operatorname{LHSV}^{-1}{ }^{-1}\right)$} & \multicolumn{2}{|c|}{$\mathrm{S}^{(\mathrm{a})}{ }_{\text {out }}(\mathrm{ppm})$} & \multicolumn{3}{|c|}{$\mathrm{S}_{\text {in }} / \mathrm{S}_{\text {out }}$} & $\mathrm{N}^{(\mathrm{a})}{ }_{\mathrm{out}}(\mathrm{ppm})$ & \multicolumn{3}{|c|}{$\mathrm{N}_{\mathrm{in}} / \mathrm{N}_{\text {out }}$} \\
\hline & & \multicolumn{2}{|c|}{470} & & \multicolumn{2}{|l|}{18.723} & 23 & \multicolumn{3}{|c|}{2.478} \\
\hline \multirow{4}{*}{310} & \multirow{2}{*}{\multicolumn{2}{|c|}{$\begin{array}{l}0.5 \\
0.4\end{array}$}} & \multicolumn{2}{|c|}{375} & & \multicolumn{2}{|l|}{23.467} & 17 & \multicolumn{3}{|c|}{3.353} \\
\hline & & & \multicolumn{2}{|c|}{290} & & \multicolumn{2}{|l|}{30.345} & 11 & \multicolumn{3}{|c|}{5.182} \\
\hline & \multicolumn{2}{|r|}{0.3} & \multirow{2}{*}{\multicolumn{2}{|c|}{$\begin{array}{l}255 \\
210\end{array}$}} & & \multicolumn{2}{|l|}{34.510} & 9 & & 6.333 & \\
\hline & \multicolumn{2}{|r|}{0.25} & & & & 41.905 & & 7 & & 8.143 & \\
\hline & & 0.6 & & & & 19.775 & & 19 & & 3.000 & \\
\hline & & 0.5 & & & & 24.444 & & 13 & & 4.385 & \\
\hline 330 & & 0.4 & & & & 33.207 & & 9 & & 6.333 & \\
\hline & & 0.3 & & & & 38.261 & & 7 & & 8.143 & \\
\hline & & 0.25 & & & & 45.128 & & 5 & & 11.400 & \\
\hline & & 0.6 & & & & 21.463 & & 15 & & 3.800 & \\
\hline & & 0.5 & & & & 26.667 & & 11 & & 5.182 & \\
\hline 350 & & 0.4 & & & & 35.918 & & 8 & & 7.125 & \\
\hline & & 0.3 & & & & 41.905 & & 5 & & 11.400 & \\
\hline & & 0.25 & & & & 48.889 & & 4 & & 14.250 & \\
\hline
\end{tabular}

$\mathrm{S}^{(\mathrm{a})}{ }_{\text {out }}, \mathrm{N}^{(\mathrm{a})}{ }_{\text {out }}=$ sulfur and nitrogen of hydrofinished LDWO

Table 3: Thermodynamic parameters of the HDS and HDN reactions for the hydrofinished LDWO. Ea of HDS $=8.601 \mathrm{~K} . \mathrm{J} . \mathrm{mol}{ }^{-1} \mathrm{Ea}$ of HDN $14.271 \mathrm{~K} . \mathrm{J} . \mathrm{mol}^{-1}$

\begin{tabular}{lllllllll}
\hline \multicolumn{3}{c}{ 14.271 K. J.mol } \\
\hline
\end{tabular}

The studies were conducted with the aim of reaching the optimum operating conditions that would lead to the production of high quality ATF oil from LDWO.

Effect of hydrogen/feedstock ratio on the hydrofinished lubricating oil properties: The effect of $\mathrm{H}_{2}$ /feedstock ratio on the physicochemical properties of the hydrofinished LDWO of WD origin has been studied by increasing $\mathrm{H}_{2} / \mathrm{HC}$ ratio from 400 to 1400 $\mathrm{Nm}^{3} / \mathrm{M}^{3}$ gradually. Other operating conditions were kept at constant values, (temperature $=290{ }^{\circ} \mathrm{C}$, pressure $=130 \mathrm{~kg} \mathrm{~cm}^{-2}$ and LHSV $=0.4 \mathrm{~h}^{-1}$ ).
The increase in the $\mathrm{H}_{2}$ to $\mathrm{HC}$ feed ratio from 400 to $800 \mathrm{Nm}^{3} \mathrm{M}^{-3}$ is apparently decreased the nitrogen, sulfur and acidity contents of the hydrofinished oil. These observation are probably due to the hydrogenation of nitrogen, sulfur and oxygen containing compounds with the liberation of $\mathrm{NH}_{3}, \mathrm{H}_{2} \mathrm{~S}$ and $\mathrm{H}_{2} \mathrm{O}$. On the other hand, the specific gravity, refractive index, UV absorbance at $275 \mathrm{~nm}$ and the aromatic carbon, $\mathrm{C}_{\mathrm{A}} \%$ are decreased leading to a lighter oil with HCs of lower aromaticity. The viscosity of the hydrofinished oil is remained nearly constant while the VI is slightly increased. These results are associated with an increase in the $\mathrm{C}_{\mathrm{N}} \%$ confirming that naphthenic 
hydrocarbons are characterized by better viscositytemperature properties that their corresponding $\operatorname{aromatics}^{[28,29]}$.

The comparison between the different technological parameters which are affecting the hydrofinishing process. Table 1 show that the increase of $\mathrm{H}_{2} / \mathrm{HC}$ ratio has the most influential contribution on the process in terms of sulfur, nitrogen and acidity contents of the product. Further increase in $\mathrm{H}_{2} / \mathrm{HC}$ feed ratio over did not significantly improve the quality of the hydrofinished oils. However, it will lead to an increase in the cost of the process with respect to hydrogen consumption and its recycling facilities ${ }^{[30]}$.

Effect of reactor pressure on the hydrofinished lubricating oil properties: The effect of reactor pressure on the physicochemical properties of the hydrofinished lubricating oil has been studied at five operating pressure ranging from 100 to $135 \mathrm{~kg} \mathrm{~cm}^{-2}$, meanwhile the other operating factors were kept constant, (temperature $=290{ }^{\circ} \mathrm{C}$, LHSV $=0.4 \mathrm{~h}^{-1}$ and hydrogen/feedstock ratio of $800 \mathrm{Nm}^{3} \mathrm{M}^{-3}$ ). Table 1 shows that the increase of the operating pressure from 100 to $130 \mathrm{~kg} \mathrm{~cm}^{-2}$ led to a substantial decrease in the values of the specific gravity, RI, color, VI, sulfur and nitrogen contents, pour point, VGC and the UV absorbance@275 nm. Therefore, increasing the applied pressure in the hydrofinishing process to $130 \mathrm{~kg}$ $\mathrm{cm}^{-2}$ improved most of the specified physicochemical properties of the LDWO. This is probably through the increasing the possibility of feed and hydrogen stream contacts with the catalyst. However, increasing the pressure from 100 to $135 \mathrm{~kg} \mathrm{~cm}^{-2}$ had slight impact on the hydrocarbon composition of the produced oils, where aromatics, naphthenic and paraffinic carbon percentages $\left(\mathrm{C}_{\mathrm{A}}, \mathrm{C}_{\mathrm{N}}\right.$ and $\left.\mathrm{C}_{\mathrm{P}} \%\right)$ remained nearly constant. This also indicates that the improvement in the properties of the produced oil is mainly due to the removal of nitrogen, sulfur and oxygen containing compounds $^{[31]}$.

The increase of the pressure in the hydrofinishing process gives a good improvement in color degree, viscosity and carbon residue, Table 1 . The results can be attributed to the removal of the highly colored compounds such as poly-aromatics, or the change of sulfur compounds to simple ones of lower color, as well as removing other impurities. The viscosity decreased by increasing the pressure probably due to the saturation of the unsaturated hydrocarbons and the saturation reactions lead to the formation of oils with low carbon residue and higher hydrogen/carbon ratio. Table 1 shows no significant improvement in the pour point of the produced hydrofinished oil and this suggest increasing the working pressure has slightly effect on the paraffin content $\left(\mathrm{C}_{\mathrm{p}} \%\right)$ of the LDWO. Finally we can conclude, that greater conversion of impurities may be achieved by increasing hydrogen pressure and the increase in hydrogen pressure favors the hydrogenation reactions and reduces polymerization reactions and coke formation. However, working at pressure equal to $130 \mathrm{~kg} \mathrm{~cm}^{-2}$ compromise between the quality of the produced oil and the capital cost of the process.

Effect of reactor temperature on the hydrofinished lubricating oil properties: The effect of temperature on the hydrofinishing process of LDWO was studied at operating temperature ranging from 250 to $350^{\circ} \mathrm{C}$. Other operating parameters were kept at constant values throughout all experiments, (pressure $=130 \mathrm{~kg} \mathrm{~cm}^{-2}$, liquid flow rate $=0.4 \mathrm{~h}^{-1}$ and hydrogen/feedstock ratio $=$ $800 \mathrm{Nm}^{3} \mathrm{M}^{-3}$ ). The applied catalyst was a presulfided mixture of $\mathrm{NiO}$ and $\mathrm{MoO}_{3}$ supported on alumina where $\mathrm{NiO}$ acts as a promoter.

The physicochemical properties of the hydrofinished LDWO show that the sulfur content is sharply decreased from 8800 to $460 \mathrm{ppm}$ at $250^{\circ} \mathrm{C}$ and is remained containing $360 \mathrm{ppm}$ sulfur by increasing the temperature up to $350^{\circ} \mathrm{C}$, Table 1 . The unchanged sulfur amount can be ascribed to the lowest hydrodesulfurization reactivity of the stericaly hindered sulfur compounds such as 4,6-alkyl-dibenzothiophenes concentrated in middle distillates ${ }^{[32]}$. On other words, as the reactor temperature increases to $330^{\circ} \mathrm{C}$ the sulfur content and total acidity decrease. Increasing the temperature will increase the rate of the hydrodesulfurization reactions, facilitate the removal of the sulfur from the relatively stable sulfur heterocyclic compound and probably leads to the reduction of naphthenic acids ${ }^{[33]}$. Moreover, the decrease in the amounts of sulfur, nitrogen and acidic content is occurred with parallel increase in the average molecular weight of the produced oil, Table 1. This may suggest the removal of undesirable components that are associated with the removal of the lighter fraction.

The aromatic content $\left(\mathrm{C}_{\mathrm{A}} \%\right)$ was decreased and the naphthenic content $\left(\mathrm{C}_{\mathrm{N}} \%\right)$ was increased with increasing the operating temperature. This indicates that the temperature of the hydrofinishing process is potentially affected the hydrocarbon structures. Another related property is the viscosity index (VI) that is usually used as an indicator of the rate of viscosity change with temperature. According to the data listed in Table 1, the VI has been improved from 96 to 101 by increasing the temperature from 250 to $330^{\circ} \mathrm{C}$. It is known that the increasing of paraffinic hydrocarbon gives raise to the VI values increase while the aromatics decrease this value. This observation has been noticed before and is interpreted in terms of the saturation of polycyclic aromatic hydrocarbons into the corresponding naphthenes ${ }^{[33,34]}$. At $350^{\circ} \mathrm{C}$, the VI value is slightly decreased that may be attributed to the occurrence of undesirable side reactions such as polymerization and cracking at this temperature. The viscosity gravity constant (VGC) values are usually referred to the higher aromatic contents and the greater rate of viscosity change with the change in 
Am. J. Applied Sci., 3 (12): 2136-2146, 2006

Table 4 : Effect of multipurpose additives Infenium and Lubrizol on the physicochemical properties of the hydrofinished LDWO.

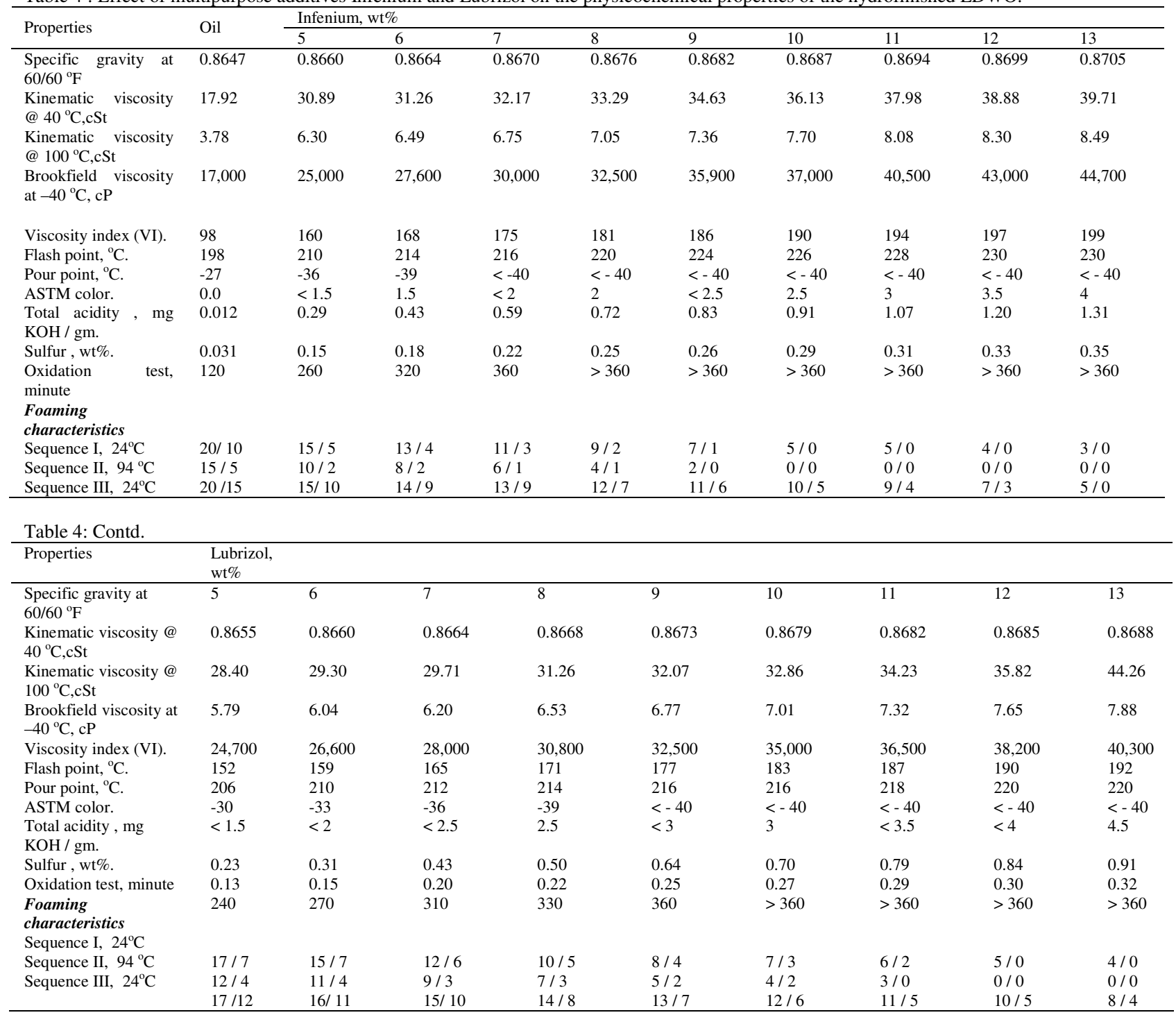

temperature ${ }^{[35]}$. In the present study, as the temperature is increased from 250 to $330^{\circ} \mathrm{C}$ the $\mathrm{VGC}$ and $\mathrm{C}_{\mathrm{A}} \%$ values are decreased from 0.8185 to 0.8146 and from 5.50 to 1.34 , respectively.

These results agree with the reported conclusion that the aromatic compounds possess poor viscositytemperature characteristic and the removal of aromatic compounds improves the viscosity index of the hydrofinished oil ${ }^{[32]}$. Also, increasing of hydrofinishing temperature led to an improvement in the oil color due to the reduction of the impurity content of the oil, namely, heavy aromatics sulfur, oxygenated compounds and other impurities. These impurities are relatively reactive species and readily oxidized by atmospheric oxygen during storage and application leading to the formation of dark colored compounds.

Effect of liquid hourly space velocity (LHSV) on the hydrofinished lubricating oil properties: LHSV measures the contact time between the hydrocarbon and catalyst in the reactors and it is expressed as a liquid volumetric ratio of the hourly hydrocarbon feed rate $\left(\mathrm{M}^{3} \mathrm{~h}^{-1}\right)$ divided by the total catalyst volume $\left(\mathrm{M}^{3}\right)$. It is proportional to the inverse of the residence time $\left(\mathrm{h}^{-1}\right)$. The effect of LHSV on the quality of the hydrofinished LDWO was studied and tabulated in Table 1. It can be deduced that the decreasing of the space velocity from 0.6 to $0.3 \mathrm{~h}^{-1}$ led to a decrease in the values of specific gravity, refractive index, color, sulfur and nitrogen contents, acidity, carbon residue, UV absorbance and VGC. However further decrease of LHSV from 0.3 to $0.25 \mathrm{~h}^{-1}$ led to an increase of these properties ${ }^{[37]}$. Furthermore, the viscosity temperature property of the oils expressed as VI is slightly improved from 96 to 100 by decreasing the LHSV to $0.3 \mathrm{~h}^{-1}$. This trend could be attributed to that, decreasing of LHSV leads to an increase of the contact time between the feed, hydrogen stream and catalyst and therefore these will increase the 
reaction rate. Consequently, this will increase the removal of impurities and improve the quality of the hydrofinished oil. Further increase of LHSV more than $0.25 \mathrm{~h}^{-1}$ will increase the contact time between the feedstock and the catalyst may promote undesirable reactions which lowered the quality of the hydrofinished oil ${ }^{[36]}$.

Effects of temperature and space velocity on the HDS and HDN reactions: Thermodynamic treatment: The thermodynamic parameters of the influence of the hydrofinishing temperature and LHSV on the HDS and HDN reactions of the investigated oil were quantitavely measured.

Landau et al. ${ }^{[36]}$, indicated that the values of activation energy of HDS and HDN reactions are increased by increasing hydrofinishing temperature. As previously reported, the differences in the activation energies of HDS and HDN are as a result of the different reactivities of sulfur and nitrogen containing compounds with temperature which promotes the catalyst activity ${ }^{[36]}$.

The measurements in the present study indicate that, the LHSV range yielded an almost complete conversion of sulfur, while the decrease of HDN extent by about $77 \%$ (at $290^{\circ} \mathrm{C}$ and LHSV $0.4 \mathrm{~h}^{-1}$ ). At constant hydrofinishing temperature, decreasing the LHSV from 0.6 to $0.25 \mathrm{~h}^{-1}$ has substantial effect on the reactivity of HDS and HDN reactions. Also, this reactivity was increased with raising hydrofinishing temperature up to $350{ }^{\circ} \mathrm{C}$, Table 2 .

Equation for hydrodesulfurization and hydrodenitrogenation reactions is assumed to be first order and expressed as ${ }^{[25]}$ :

$\ln \left(\mathrm{C}_{\text {in }} / \mathrm{C}_{\text {out }}\right)=\mathrm{k} / \mathrm{LHSV}$

Where:

$\mathrm{C}_{\mathrm{in}}=$ concentration of sulfur or nitrogen $\left(\mathrm{S}_{\mathrm{in}}\right.$ or $\left.\mathrm{N}_{\mathrm{in}}\right)$ in reactor inlet

$\mathrm{C}_{\text {out }}=$ concentration of sulfur or nitrogen $\left(\mathrm{S}_{\text {out }}\right.$ or $\left.\mathrm{N}_{\text {out }}\right)$ in reactor outlet

$\mathrm{K}=$ apparent reaction rate constant $\left(\mathrm{h}^{-1}\right)$

LHSV = liquid hourly space velocity $\left(\mathrm{h}^{-1}\right)$

According to data in Table $2, \log \left(\mathrm{S}_{\text {in }} / \mathrm{S}_{\text {out }}\right)$ and $\log$ $\left(\mathrm{N}_{\text {in }} / \mathrm{N}_{\text {out }}\right)$ were plotted against 1/LHSV as in Fig. 2 a,b. The reaction rate constants $(\mathrm{k})$ were determined from the slopes of curves. Figure $2 \mathrm{c}$ was used for the calculation of the values of apparent activation energy (Ea) for HDS and $\mathrm{HDN}$ reactions based on rate constants calculated from Fig. 2a,b (equation 1). The values of Ea and the intercepts of Fig. 2a, b were used for the calculation of the values of the enthalpy of activation $\Delta \mathrm{H}$, entropy of activation $\Delta \mathrm{S}$ and free energy of activation $\Delta \mathrm{G}$.

The values of $\mathrm{E}$ are found to be 8.601 and 14.271 $\mathrm{K} \mathrm{J} \mathrm{mol}^{-1}$ for HDS and HDN reactions, respectively. i.e. HDS is easier to occur than HDN reaction. This could be attributed to the effect of $\mathrm{H}_{2} \mathrm{~S}$ and $\mathrm{NH}_{3}$ on the hydrofinishing reactions. It is well established that hydrogen sulfide and ammonia enhance desulfurization, while hydrogen sulfide inhibits denitrogenation reactions.

Table 3 indicated that, the values of $\Delta \mathrm{G}$ for HDS and HDN are increased with increasing temperature, which indicate that HDS and HDN processes are more faster at higher temperature. Raising the temperature leads to increasing the kinetic energy of reactants and facilitates the above mentioned reactions. The values of $\Delta \mathrm{S}$ for HDS and HDN are decreased with increasing temperature which indicate that, the two processes are less ordered at high temperature.

Formulation of ATF through the upgrading of the hydrofinished LDWO using additives: Automatic transmission fluids (ATFs) are the most important lubricating oils in many purposes, including heat dissipation, wear protection, lubrication from inhibition and shift transmission. It is usually produced through the upgrading of the hydrofinished LDWO using additives $^{[39,40]}$.

The hydrofinished LDWO of WD crude oil, that was obtained from carrying out the previously mentioned refining processes at their optimum conditions, were evaluated as a basestock for formulating the automatic transmission fluid (ATF). The solvent extraction process was achieved using NMP to feed ratio 2: 1 and extraction temperature $55^{\circ} \mathrm{C}$, while the solvent dewaxing process was applied using MEK/toluene (60: 40) to raffinate ratio 4: 1 and filtration temperature $-42^{\circ} \mathrm{C}$. The hydrofinishing process was operated at temperature $290^{\circ} \mathrm{C}$, pressure $130 \mathrm{~kg} \mathrm{~cm}^{-2}$, LHSV $0.4 \mathrm{~h}^{-1}$ and hydrogen to feed ratio 800: $1 \mathrm{Nm}^{3} \mathrm{M}^{-3}$.

Formulation of ATF as a final product are enhanced by the use of different types of additives, to withstand any operating conditions. These additives are viscosity index improver, pour point depressant, antioxidant, anti-wear, anti-rust, anti-foam, seal swelling agents, corrosion inhibitors and detergent/dispersant ${ }^{[41]}$. Most of these additives are included in the multipurpose commercial additive packages. Automatic transmission fluid packages may contain up to 20 separate components which are finely tuned to provide optimum performance including delicately balanced friction characteristics ${ }^{[15]}$.

In view of these considerations, comparative studies on the compatibility and the effect of two multipurpose commercial packages Infenium T442 and Lubrizol@6701 D together and with the formulated additives on the VI and pour point of the hydrofinished LDWO were found to be highly informative.

Infenium T442 is a lubricant additive containing polyolefin amide alkylene amine, poly long chain alkylmethacrylate, zinc alky dithiophosphate (Zn DTPs) and other components that are dissolved in highly refined mineral oil. Lubrizol ( ${ }^{\circ} 6701 \mathrm{D}$ is a multi purpose package for automatic transmission fluids. 
Table 5: Effect of changing the VI improver on the physicochemical properties of the hydrofinished LDWO. Anti-oxidant $=1.5, \mathrm{wt} \%, \quad$ anti-wear $=1, \mathrm{wt} \%$

\begin{tabular}{|c|c|c|c|c|c|c|c|c|c|c|}
\hline \multirow[b]{2}{*}{ Properties } & \multirow{2}{*}{ Oil } & \multicolumn{9}{|c|}{ VI, wt \% } \\
\hline & & 2 & 2.5 & 3 & 3.5 & 4 & 4.5 & 5 & 5.5 & 6 \\
\hline Specific gravity at $60 / 60^{\circ} \mathrm{F}$ & $0 . .8647$ & 0.8656 & 0.8660 & 0.8663 & 0.8667 & 0.8669 & 0.8670 & 0.8673 & 0.8675 & 0.8676 \\
\hline Kinematic viscosity @40 $0^{\circ} \mathrm{C}, \mathrm{cSt}$ & 17.92 & 28.47 & 29.33 & 29.80 & 30.67 & 31.39 & 32.66 & 33.18 & 34.11 & 34.58 \\
\hline Kinematic viscosity @ $100^{\circ} \mathrm{C}, \mathrm{cSt}$ & 3.78 & 5.73 & 5.96 & 6.13 & 6.39 & 6.61 & 6.89 & 7.09 & 7.36 & 7.52 \\
\hline Brookfield viscosity at $-40^{\circ} \mathrm{C}, \mathrm{cP}$ & 17,000 & 24,500 & 25,400 & 27,000 & 28,500 & 30,200 & 32,000 & 33,800 & 35,500 & 37,000 \\
\hline Viscosity index (VI) & 98 & 148 & 154 & 160 & 167 & 173 & 178 & 184 & 190 & 194 \\
\hline Flash point, ${ }^{\circ} \mathrm{C}$ & 198 & 204 & 206 & 208 & 210 & 212 & 212 & 216 & 218 & 220 \\
\hline Pour point ${ }^{\circ} \mathrm{C}$ & -27 & -33 & -36 & -39 & -39 & $<-40$ & $<-40$ & $<-40$ & $<-40$ & $<-40$ \\
\hline ASTM color & 0.0 & $<1.5$ & 1.5 & $<2$ & 2.5 & $<3$ & 3.5 & 3.5 & $<4$ & 4 \\
\hline Total acidity, mg KOH/gm & 0.012 & 0.32 & 0.46 & 0.63 & 0.77 & 0.84 & 0.93 & 1.11 & 1.24 & 1.35 \\
\hline Sulfur, wt \% & 0.031 & 0.149 & 0.147 & 0.145 & 0.143 & 0.140 & 0.139 & 0.137 & 0.135 & 0.134 \\
\hline Oxidation test, minute & 120 & $>360$ & $>360$ & $>360$ & $>360$ & $>360$ & $>360$ & $>360$ & $>360$ & $>360$ \\
\hline Foaming characteristics & & & & & & & & & & \\
\hline Sequence I, $24^{\circ} \mathrm{C}$ & $20 / 10$ & $18 / 9$ & $17 / 9$ & $17 / 8$ & $16 / 8$ & $16 / 7$ & $16 / 7$ & $15 / 7$ & $15 / 7$ & $14 / 6$ \\
\hline Sequence II, $94{ }^{\circ} \mathrm{C}$ & $15 / 5$ & $13 / 4$ & $13 / 4$ & $12 / 4$ & $12 / 4$ & $11 / 4$ & $11 / 3$ & $11 / 3$ & $10 / 3$ & $10 / 3$ \\
\hline Sequence III, $24^{\circ} \mathrm{C}$ & $20 / 15$ & $18 / 13$ & $18 / 12$ & $17 / 12$ & $17 / 11$ & $17 / 11$ & $17 / 10$ & $16 / 10$ & $15 / 10$ & $15 / 9$ \\
\hline
\end{tabular}

Table 6: The Protection efficiency (P)obtained by impedance measurements for the hydrofinished LDWO with Infenium, Lubrizol and Formulated additives

\begin{tabular}{|c|c|c|c|c|c|c|c|c|c|c|c|c|c|c|c|c|}
\hline \multirow[b]{2}{*}{$\begin{array}{l}\text { Additive } \\
\text { (wt\%) }\end{array}$} & \multicolumn{5}{|l|}{ Infenium } & \multicolumn{5}{|l|}{ Lubrizol } & \multirow[b]{2}{*}{$\begin{array}{l}\text { VI } \\
\text { (wt\%) }\end{array}$} & \multicolumn{5}{|c|}{ Formulated } \\
\hline & $\begin{array}{ll}\mathrm{R}_{\mathrm{s}} & \mathrm{X} \\
10^{+8} & \end{array}$ & $\begin{array}{l}\left(\mathrm{R}_{\mathrm{p}}\right) \mathrm{O} \times \\
10^{+8}\end{array}$ & $\begin{array}{l}\mathrm{CPE} / \mathrm{F} \\
\times 10^{-14}\end{array}$ & $\mathrm{~N}$ & $P$ & $\begin{array}{ll}\mathrm{R}_{\mathrm{s}} & \mathrm{x} \\
10^{+8} & \end{array}$ & $\begin{array}{l}\left(\mathrm{R}_{\mathrm{P}}\right) \mathrm{O} \\
\mathrm{x} 10^{+8}\end{array}$ & $\begin{array}{l}\mathrm{CPE} / \mathrm{F} \times \\
10^{-14}\end{array}$ & $\mathrm{~N}$ & $P$ & & $\begin{array}{ll}\mathrm{R}_{\mathrm{s}} & \mathrm{x} \\
10^{+8} & \end{array}$ & $\begin{array}{l}\left(\mathrm{R}_{\mathrm{P}}\right) \mathrm{o} \\
\mathrm{x} \\
10^{+8} \\
\end{array}$ & $\begin{array}{l}\mathrm{CPE} / \mathrm{F} \\
\times 10^{-14}\end{array}$ & $\mathrm{~N}$ & $P$ \\
\hline Oil. & -0.1583 & 0.1700 & 10.50 & 0.764 & & & & & & & & & & 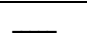 & & \\
\hline 5 & -2.681 & 175.1 & 25.61 & 0.799 & 99.903 & -11.10 & 2139.0 & 50.78 & 0.850 & 99.92 & 2 & -3.742 & 18.97 & 2.881 & 0.893 & 99.10 \\
\hline 6 & -3.663 & 146.7 & 0.7252 & 0.861 & 99.884 & -1.757 & 1814.0 & 2503.0 & 0.975 & 99.91 & 2.5 & -.2963 & 16.62 & 39.43 & 0.781 & 98.98 \\
\hline 7 & -0.1127 & 122.3 & 288.6 & 0.904 & 99.861 & -2.374 & 1634.0 & 28.46 & 0.817 & 99.90 & 3 & -63.71 & 14.30 & 0.6817 & 0.901 & 98.81 \\
\hline 8 & -14.18 & 109.9 & 2.635 & 0.767 & 99.850 & -8.795 & 1427.0 & 6.413 & 0.736 & 99.88 & 3.5 & 0.06543 & 13.12 & 4.719 & 0.834 & 98.70 \\
\hline 9 & 0.2732 & 109.0 & 3.597 & 0.778 & 99.844 & -34.03 & 127.3 & 0.04962 & 0.691 & 99.87 & 4 & -2.426 & 9.987 & 3651.0 & 0.691 & 98.30 \\
\hline 11 & -0.3171 & 96.46 & 35.56 & 0.826 & 99.824 & 1.938 & 109.3 & 1934.0 & 0.973 & 99.85 & 5 & 3.721 & 6.831 & 6.183 & 0.768 & 97.51 \\
\hline 12 & -43.41 & 81.36 & 741.5 & 0.729 & 99.791 & 2.664 & 77.83 & 253100.0 & 0.898 & 99.78 & 5.5 & -27.61 & 6.138 & 21.67 & 0.903 & 97.23 \\
\hline 13 & -5.397 & 71.17 & 1.615 & 0.7511 & 99.760 & 0.4654 & 52.82 & 6517.0 & 0.969 & 99.68 & 6 & -0.6318 & 5.963 & 61520.0 & 0.867 & 97.15 \\
\hline
\end{tabular}

The formulated additive was prepared by adding different percentages of viscosity index improvers, $1.5 \mathrm{wt} \%$, anti-oxidant and $1 \mathrm{wt} \%$ anti-wear.

The importance of Zn DTPs (structure I) as additives for lubricating oils is due to their multifunctional performance. Not only do they act as anti-oxidants, but they also improve the wear inhibition of the lubricant and protect metals against corrosion ${ }^{[42]}$. Several studies have explained the Zn DTP anti-wear action. They have suggested that molecules of Zn DTP are adsorbed on mechanically activated metal surface participate in the surface of polyphosphate tribofilm formation under conditions of boundary lubrication. Zinc poly thio phosphate "thermal film" have been recently recognized to be precursor reaction products in the formation of polyphosphate glasses tribofilm ${ }^{[43]}$.

The way that Zn DTP performs as an anti-oxidant is a complex interaction pattern involving hydroperoxides and the anti-oxidant mechanism peroxy radicals. It was demonstrated that is proceeded via acid catalyzed ionic decomposition of the hydroperoxide.

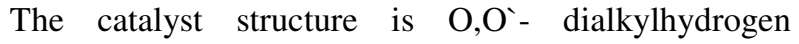
dithiophosphate, $(\mathrm{RO})_{2} \mathrm{PS}_{2} \mathrm{H}$, that derived from the $\mathrm{Zn}$ $\mathrm{DTP}^{[44]}$. Infenium T442 also contains poly long chain alkyl methacrylate (structure II) and polyolefin amide alkylene amine in order to incorporate anti-wear, pour point depressant and dispersancy to reach the basic viscosity control properties. The multipurpose packages incorporate alkylated phenol, long chain alkyl salicylate and sulfurized alkyl phenate. They act as detergent/dispersants and as oxidation inhibitors due to the presence of phenolic function group ${ }^{[42-44]}$.

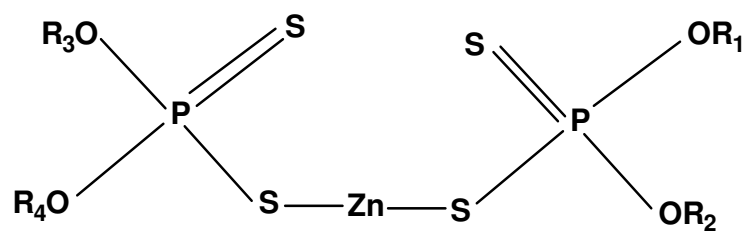

I. Zinc Alkyl Dithiophosphates

$\mathrm{R}$ can be alkyl, aryl or alkyl-aryl

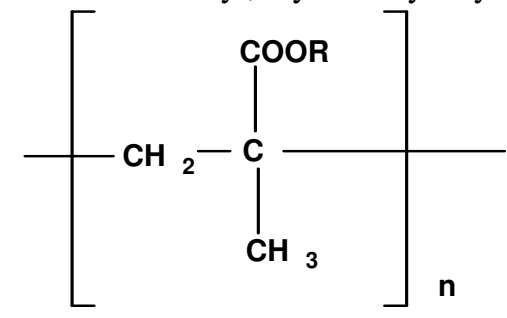

II. Poly Long Chain Alkyl Methacrylate

Determination of the corrosion rates by AC impedance method measurements for the automatic transmission fluids: Electrochemical impedance is the more appropriate method for many corrosion studies, particularly for corrosion rate determination, 


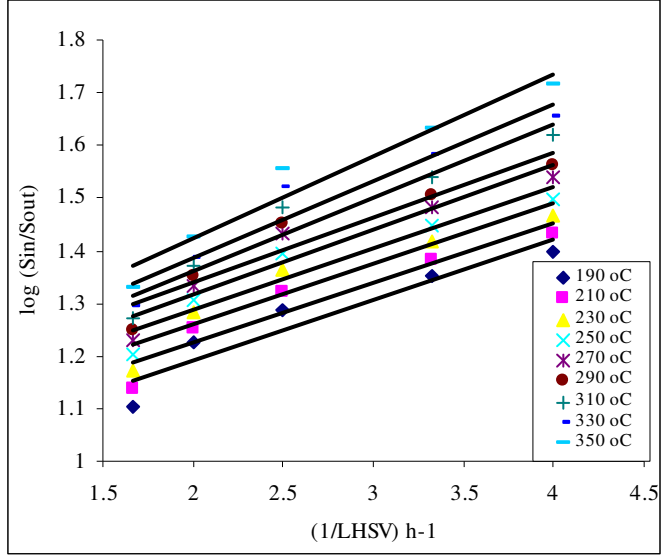

Fig. 2a: Relation between log (Sin / Sout) and 1/LHSV for HDS reactions at different temperatures

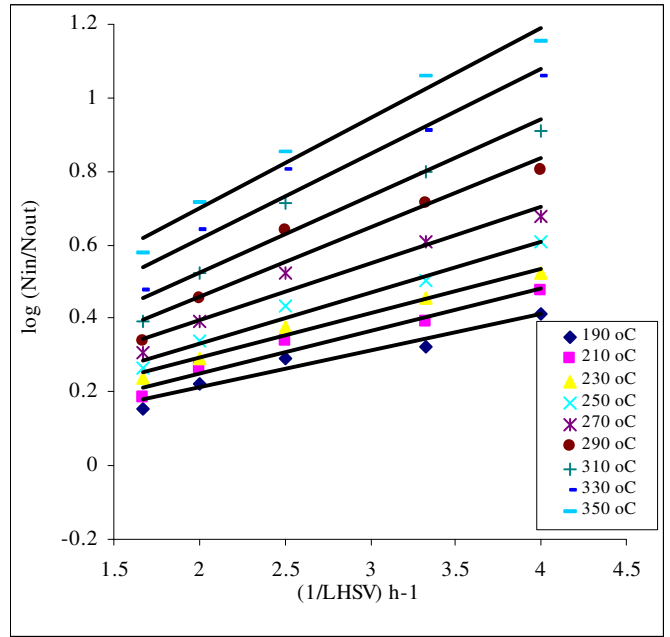

Fig. 2b: Relation between $\log$ (Nin / Nout) and 1/LHSV for HDN reactions at different temperatures

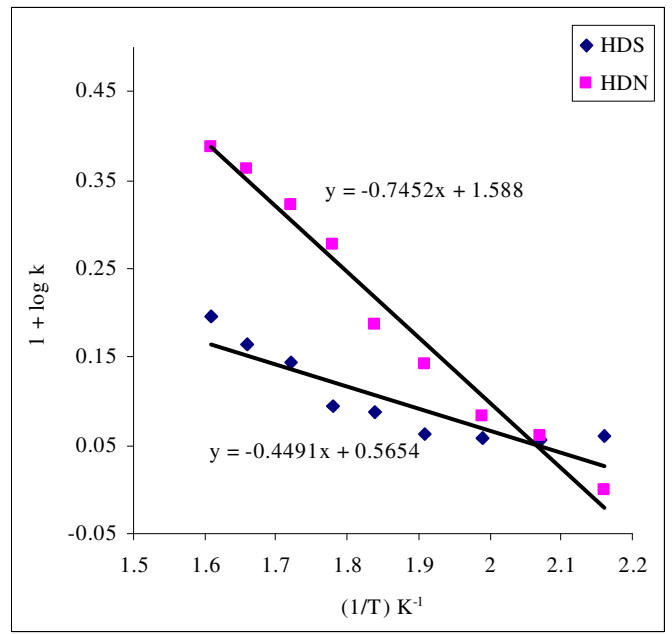

Fig. 2c: Relation between $\log \mathrm{k}$ and 1/T for HDS and HDN reactions

mechanistic studies and the investigation of inhibited systems. The impedance measurements typically gave a single relation or semicircle comprising the charge

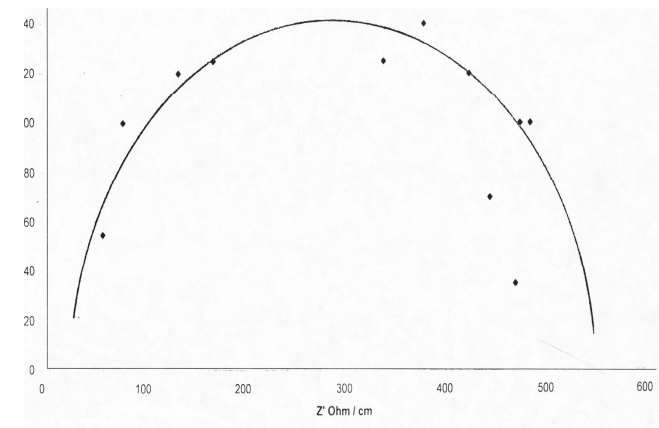

a) Infenium (7, wt \%)

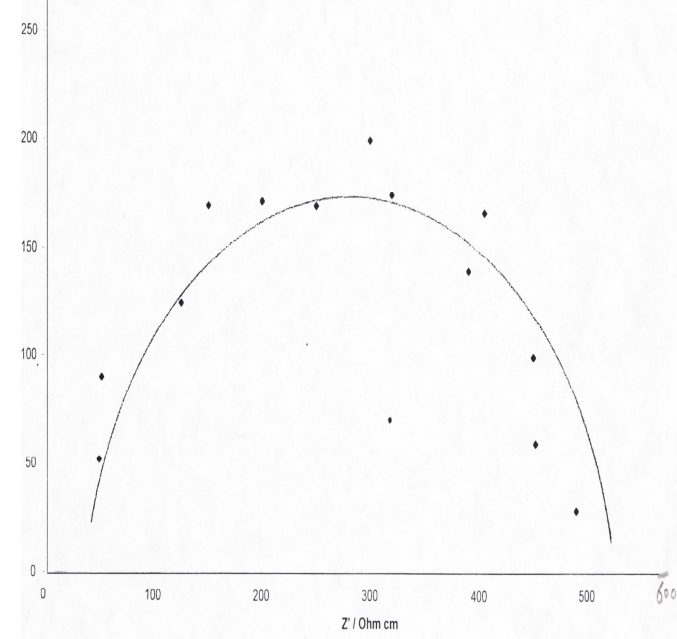

b) Lubrizol $(9$, wt $\%)$

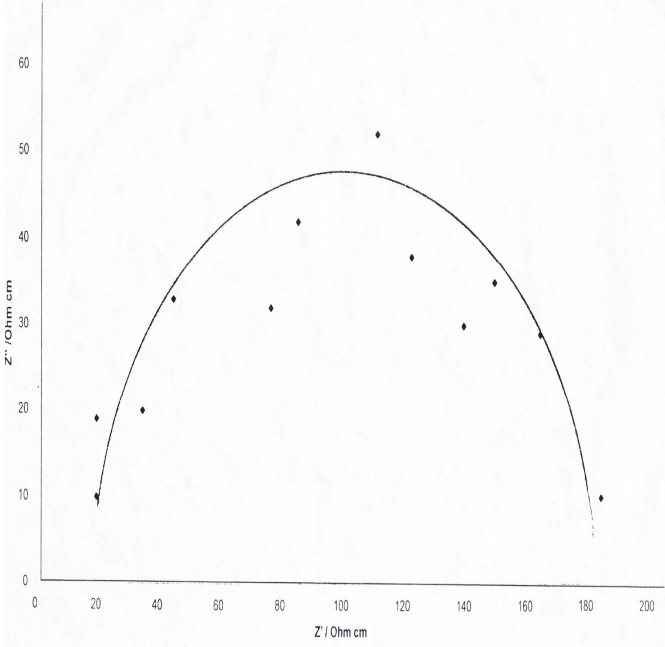

c) Formulated (4 VI, wt \%)

Fig. 3: Impedance measurements for the hydrofinished LDWO with additives

transfer resistance in parallel with the double layer capacitance ${ }^{[27]}$. Additive efficiencies and the adsorption isotherms were calculated from the charge transfer resistance value. In addition, the capacitance-potential diagrams would provide mechanistic information on the adsorption type of compounds. AC impedance measurements were used primarily to calculate the capacity of the double layer. On the addition of an 
additive, change in the double layer is expected to reflect the structural modifications of the metal solution interphase due to the adsorption of the inhibitor molecules on the metal surface ${ }^{[45]}$.

AC impedance technique was applied to study the effect of the increase sulfur and total acidity on the corrosion rates of carbon steel coupons that contact the ATF when using the lubricating oil.

Table 6 compile the impedance measurements and the protection efficiencies for the hydrofinished and non-hydrofinished LDWO of WD origin with Infenium T442, Lubrizol ${ }^{\circledR} 6701 \mathrm{D}$ and formulated additives.

The impedance measurements of carbon steel coupons at rest potential and ambient temperature give value of $(\mathrm{Rp})_{0}=1.7 \times 10^{+7}$ for the hydrofinished LDWO of WD crude oil. When the coupons was immersed in the hydrofinished LDWO in the presence of $\mathrm{T} 442$, the values of $(\mathrm{Rp})_{0}=1.751 \times 10^{+10}$ and protection efficiency 99.903 . The protection efficiency was decreased with increasing the additive concentrations and consequently the protection efficiency was nearly constant, 99.76. For Lubrizol R $6701 \mathrm{D}$, the protection efficiency was changed from 99.92 to 99.68 on adding 5 and $13 \%$ wt of additive with the hydrofinished LDWO.

The protection efficiency for the formulated additive was found 99.10 corresponding to $2 \% \mathrm{VI}, 1.5$ anti-oxidant and $1 \%$ anti-wear and it was decreased until it was reached to 97.15 at $6 \%$ viscosity index, $1.5 \%$ anti-oxidant and $1 \%$ anti-wear.

Figure 3 shows the impedance complex diagrams of carbon steel coupons in the hydrofinished LDWO in the absence and presence of 7\% Infenium, 9\% Lubrizol and with formulated additive containing $4 \mathrm{wt} \% \mathrm{VI}$ improver, respectively after 15 minute immersion at ambient temperature. The impedance diagrams gave a semicircle type appearance for all examined additives indicating that the corrosion process of carbon steel in the hydrofinished LDWO is controlled by a charge transfer process and the presence of abovementioned additives does not alter this mechanism.

From the above mentioned results, it is concluded that, the increase of additive percents led to slightly decrease in the protection efficiency (decrease in the values of the charge transfer resistance $R_{p}$ ) i.e. the effect of these additives on the corrosion of carbon steel coupons can be negligible.

\section{CONCLUSION}

The light dewaxed oil produced from Western Desert of Egypt crude oils had a relatively high VI 96 and low pour point $-30{ }^{\circ} \mathrm{C}$. Regarding to the hydrofinishing cost and the quality of the hydrofinished oil, the optimum conditions for the hydrofinishing process were at reactor temperature $290{ }^{\circ} \mathrm{C}$, pressure $130 \mathrm{~kg} \mathrm{~cm}^{-2}$, LHSV $0.4 \mathrm{~h}^{-1}$ and $\mathrm{H}_{2} / \mathrm{HC}$ ratio $800 \mathrm{Nm}^{3}$ $\mathrm{M}^{-3}$. The ATF Dexron IID with standard specifications; viscosity index $172(\min )$ and pour point - $40(\max )$ was produced by adding $7 \mathrm{wt} \%$ from Infenium T 442 or by adding 9 wt $\%$ from Lubrizol $® 6701$ D. Infenium T442 was more preferable than Lubrizol (® 6701D because it is less expensive and requires less amounts to achieve ATF Dexron IID. Also, ATF Dexron IID with standard specifications was produced using a formulated additive containing $4 \mathrm{wt} \%$ VI, $1.5 \%$ antioxidant and $1 \mathrm{wt} \%$ anti-wear.

\section{ACKNOWLEDGMENT}

Ahmed Aly wish to express his gratitude to Alexandria Mineral Oils Company (AMOC) for providing the necessary materials and equipments for the present study.

\section{REFERENCES}

1. Goyan R.L., R.E. Melley, P.A. Wissner and W.C. Ong, 1998. Biodegradable lubricants. Lubrication Engg., 54: 10-17.

2. Alan, G.L., 2000. Modern Petroleum Technology. John Wiley, Sons Ltd., pp: 311-334.

3. Henderson, H.E., 1999. Advanced performance products from VHVI specialty base fluids. Am. Chem. Soc., 44: 251-256.

4. Burris, D.R., 1992. Desalting crude oil. Petroleum Processing Handbook, Marcel Dekker, pp: 666677.

5. Sappington, J.M. and C.A. Armbrister, 1993. Revamp of crude vacuum tower using a total quality approach. Paper no. AM-93-64, Presented at the 1993. NPRA Annal Meeting San Antonio.

6. Erikh, V.N., M.G. Rasina and M.G.Rudin, 1988. The Chemistry and technology of petroleum and gas. Mir publisher, Moscow, pp: 103-117.

7. Sequeira, A., 1986. Furfural, N-methyl-2pyrrolidone and phenol refining of lube oil base stocks. Paper Presented at the BASF NMP Lubes Refining Seminar, Woodlands, Texas, USA.

8. Rossi, A., 1990. Lube manufacturing technology and the wax composition of base stocks. Amer. Chem. Soc., 35: 252-257.

9. Sequeira, A., 1992. Lubricating oil manufacturing processes. Petroleum Processing Handbook, Marcel Dekker, New York, pp: 634-647.

10. Vizner, S., 1992. Texaco dewaxing-wax fractionation process technology. Texaco Technology Conference Arab Oil and Gas Show Dubai, UAE.

11. Jorge, C. and M.P. Jose, 2005. Optimal scheduling of a lube oil plant. Computers and Chem. Engg., 29: 1329-1344.

12. Sequeira, A., 1994. Lubricant Base Oil and Wax Processing. Marcel Dekker, Inc., New York, pp: 225-257. 
13. Abou, El Naga, H.H. and M.A. Abdel Ghany, 1987. Chemical structure bases for oxidation stability of neutral base oils. ASLE Trans., 30: 261268.

14. Abou El Naga, H.H. and A.E.M. Salem, 1987. Testing the thermo-oxidation of lubricating oils via differential thermal analysis. J. Therm. Analysis, 32: 1401-1413.

15. Mortier, R.M. and Orszulik, 1997. Chemistry and Technology of Lubricants. $2^{\text {nd }}$ Edn., Chapman \& Hall, London, pp: 75-202.

16. Hata, H., 2002. U.S. Patent no. 20020055411.

17. Okada, K., 2002. U.S. Patent no. 20020035044.

18. TSe, K., 2003. U.S. Patent no. 20030013623.

19. Bloch, R.A., 1985. U.S. Patent no. 4, 517, 104.

20. American Society for Testing and Materials, 1997. Annual Standards (ASTM), USA, pp: 1-3.

21. Institute of Petroleum Annual Standards for Petroleum and Products, 1997. London, pp: 1,2.

22. Ho, T.C., 1988. Hydrodenitrogenation catalysts. Catal. Rev. Sci. Eng., 30: 117-123.

23. Prins, R., V.H.J. De Beer and G.A. Somorjai, 1989. Structure and function of the catalyst and the promoter in Co-Mo hydrodesulfurization. Catal. Rev. Sci. Eng., 31: 10 - 17.

24. Pasadakis, N., 2001. Characterization of hydrotreating catalysts. Appl. Catalysis A, 207: 333-341.

25. Mohammed, A.H. and Abbas, K., 1988. Residum hydrotreating-application of liquid-solid chromatography. Fuel Sci. Technol. Intl., 6: 593608.

26. Ismail, A.M. and A.M. Ahmed, 2001. Kinetics and thermodynamics of production of copper. Bull. Electrochem., 17: 385-390.

27. Galerlelli, C., M. Keddam and H. Takenouti, 1981. Alternating current impedance measurements applied to corrosion studies. Electrochemical Corrosion Testing, ASTM, STP 727, pp: 150-156.

28. Duchet, J.C., 1991. Catalytic properties of nickel molybdenum sulfides. Catal. Today, 10: 593-612.

29. Singh, I.D., 1992. Structural changes during hydrogenation of lube distillates. Fuel, 7: 13351337.
30. Miller, S.J. and J.A., Zakarian, 1991. Determination of lube hydrofinishing catalyst kinetics using ultraviolet. Ind. Eng. Chem. Res., 30: 2507-2513.

31. Wood, R.A., 1982. U.S. Patent no. 4, 311, 583.

32. Landau, M.V. and D. Givoni, 1998. Medium severity hydrotreating and hydrocracking of Israeli shale oil-II. Fuel, 77: 3-13.

33. Meyers, R.A., 1997. Handbook of Petroleum Refining Processes. Mc Graw-Hill, San Francisco, pp: 8.29-8.37.

34. Speight, J.G., 1991. The chemistry and technology of petroleum. Marcel Dekker, Inc., New York, USA, pp: 10-38.

35. Gerald, J.L. and R.P. John, 1987. How a small laboratory characterizes aromaticity in lube oil. National Lubricating Grease Institute, 50: 426-428.

36. Drahoradova, A., Z. Vit and M. Zdrazil, 1992. Carbon supported nickel-molybdenum catalyst. Fuel, 71: 455-458.

37. Galiano-Roth, A.S. and N.M. Page, 1994. Effect of hydroprocessing on lubricant base stock composition. Lubrication Engg., 50: 659-664.

38. Kanda, W., 2004. Inhibition and deactivation of hydrodenitrogenation catalysts. Energy and Fuels, 918: 539-546.

39. Masao, E. and Y. Takashi, 2005. Shear characteristics of a boundary film. Tribol. Intl., 38: 327-335.

40. Riga, A.T., 1993. Automatic transmission fluid compatibility with nylon components. Thermochemical Acta, 226: 363-368.

41. Kugimiya, T., N. Yoshimura and J. Mitsui, 1998. Tribology of automatic transmission fluid. Tribol. Lett., 5: 49-56.

42. Mc Donald, R.A., 2003. Zinc dithiophosphates. Chemical Industries, 90: 29-43.

43. Zenon, P., 2003. Tribochemistry of lubrication oils. Elsevier, New York, 1-2: 1-65.

44. Duran, A., 2006. Studying the fractional composition and oxidation stability of lube base oils. Fuel, 85: 923-928.

45. Sastri, V.S., 1997. Corrosion Inhibitors Principles and Applications. John Wiley \& Sons, New York, pp: 82-101. 